\title{
Mobile phones and head tumours. The discrepancies in cause-effect relationships in the epidemiological studies - how do they arise?
}

\author{
Angelo G Levis ${ }^{1}$, Nadia Minicuci ${ }^{2}$, Paolo Ricci ${ }^{3}$, Valerio Gennaro ${ }^{4}$ and Spiridione Garbisa ${ }^{1 *}$
}

\begin{abstract}
Background: Whether or not there is a relationship between use of mobile phones (analogue and digital cellulars, and cordless) and head tumour risk (brain tumours, acoustic neuromas, and salivary gland tumours) is still a matter of debate; progress requires a critical analysis of the methodological elements necessary for an impartial evaluation of contradictory studies.

Methods: A close examination of the protocols and results from all case-control and cohort studies, pooled- and meta-analyses on head tumour risk for mobile phone users was carried out, and for each study the elements necessary for evaluating its reliability were identified. In addition, new meta-analyses of the literature data were undertaken. These were limited to subjects with mobile phone latency time compatible with the progression of the examined tumours, and with analysis of the laterality of head tumour localisation corresponding to the habitual laterality of mobile phone use.
\end{abstract}

Results: Blind protocols, free from errors, bias, and financial conditioning factors, give positive results that reveal a cause-effect relationship between long-term mobile phone use or latency and statistically significant increase of ipsilateral head tumour risk, with biological plausibility. Non-blind protocols, which instead are affected by errors, bias, and financial conditioning factors, give negative results with systematic underestimate of such risk. However, also in these studies a statistically significant increase in risk of ipsilateral head tumours is quite common after more than 10 years of mobile phone use or latency. The meta-analyses, our included, examining only data on ipsilateral tumours in subjects using mobile phones since or for at least 10 years, show large and statistically significant increases in risk of ipsilateral brain gliomas and acoustic neuromas.

Conclusions: Our analysis of the literature studies and of the results from meta-analyses of the significant data alone shows an almost doubling of the risk of head tumours induced by long-term mobile phone use or latency.

\section{Background}

The worldwide spread of the use of MPs (mobile phones: analogue and digital cellulars, and cordless) has heightened concerns about possible adverse effects, especially head tumours. According to the International Telecommunications Union, the number of cell-phone subscriptions has reached 5 billion (mid 2010), with more than half of all users believed to be children and young adults. There are no data for cordless users, but a figure of 2 billion is a reasonable assumption. Given

\footnotetext{
* Correspondence: garbisa@unipd.ti

'Department of Experimental Biomedical Sciences, Medical School of

Padova, Padova, Italy

Full list of author information is available at the end of the article
}

these numbers, even an established modest increase (20$30 \%$ ) in tumour risk for MP users would result in significant social and health costs and individual suffering, while higher risks could give rise to a health crisis of dramatic proportions. While most technologies carry risks, these should be assessed accurately and responsibly.

MPs were introduced onto the market in the 1980s, and widely used for the following decade in the USA, the Scandinavian countries and Israel. Since the beginning of 1990s MPs have become widespread in many other countries too, with the consequence that there has been exposure to MP radiation throughout almost the entire world for at least 20 years [1-3]. Although brain

\section{() Biomed Central}


and cranial nerve tumours may have very long latency times (up to 30 years or more), it is likely that - as found with long-latency tumours due to ionizing radiations, asbestos or smoking - some due to MP will be diagnosed after just 10-15 years of MP use or latency.

The case-control studies by the Hardell group in Sweden report a statistically significant increase of at least $100 \%$ in risk of ipsilateral cerebral cancers (astrocytomas, a highly invasive glioma sub-type) and of benign tumours of the acoustic nerve (neuromas) among MP users, after use or latency period $\geq 10$ years [1-3]. It is therefore vital to understand the weight of the conflicting data from other studies which are considered reassuring in their failure to find any increased risk of head tumours in MP users $[4,5]$.

\section{Methods}

We have carried out a critical examination of the protocols and results from all case-control and cohort studies, pooled analyses and meta-analyses on head tumour risk among MP users. For each study we have identified the elements that must be taken into account to ensure an impartial evaluation of its reliability, that is: a) the number of subjects selected (cases and controls), and the percentage of their participation in the study; b) the percentage of actually exposed subjects, based on the frequency and duration of the MP use; c) the inclusion among the exposed of all users of MPs, cordless included; d) the latency and/or exposure time since first use of MPs; e) the laterality of the head tumour localization relative to the habitual laterality of MP use; f) the distribution of the relative risk (odds ratio, OR) values above and under 1, their statistical significance [95\% confidence interval (95\% CI) limits], and the probability that such distribution might be casual; g) the full and correct selection and citation of data included in the meta-analyses.

We have quantified the total number of OR values from each study, independently of sex, age, exposure time or latency of the examined subjects. Since the OR estimates reported by each author are not independent, a statistical comparison between the percentages of ORs $>1$ or $<1$ is difficult. However, a simple comparison of their percentage may indicate if their differences are more or less random, and might be due to a significantly increased risk or a substantial protective effect, or else - in the absence of plausibility of either of these effects - to errors and/or distortions in the study design.

In order to be included in our meta-analyses, studies had to have met all the following criteria:

- published in peer-reviewed journals;

- included participants using MPs since $\geq 10$ years;

- incorporated a laterality analysis of tumours.

The hypothesis test for presence of heterogeneity was based on the Q test of heterogeneity, which follows a $\chi^{2}$ distribution. Furthermore, two measures for quantifying the impact of heterogeneity were calculated: $\mathrm{H}^{2}$ (square root of the $\mathrm{Q}$ heterogeneity statistic divided by its degrees of freedom) and Higgins $\mathrm{I}^{2}$ (transformation of $\mathrm{H}$ that describes the proportion of total variation in study estimates that is due to heterogeneity). If heterogeneity was observed, then the random-effect model was performed by incorporating an estimate of the betweenstudy heterogeneity (DerSimonian and Laid $\tau^{2}$ ) into the weights. When the general fixed effect model was applied to each study estimate, a weight directly proportional to its precision was given (inverse varianceweighted method) [6].

\section{Results}

\section{MPs and head tumours: positive data}

An overview of the most significant results obtained by the Hardell group in the three pooled analyses of their data through case-control epidemiological studies referring to tumours diagnosed during 1997-2003 is given in Table 1 [1-3] With $\geq 10$-year MP use or latency, a statistically significant (s.s.) increase (ca 2- to 4-fold) in risk of overall (ipsi- plus contralateral) malign and benign brain tumours and acoustic neuromas is shown after use of analogue and digital cellulars. With cordless phone use, instead, risk is about double, s.s. only for malign brain tumours (Table 1).

As Table 1 shows, the tumour increase is chiefly localized on the habitual-use side of the head (ipsilateral tumours), and is very marked (up to 3-5 times normal incidence) and s.s. for malign brain tumours and acoustic neuromas with cellular phone use, and for astrocytomas and meningiomas with cordless use. The data for overall tumours are lower, though still considerable (up to 2-3 times normal incidence) and s.s., while the risk of contralateral tumours is not s.s., except for astrocytoma following use of cellular phones. According to Hardell, this latter finding results from the fact that the radiation produced by MPs - despite being much lower on the contralateral side - is still significant in the ventricular and subventricular space from which gliomas and (their subtype) astrocytomas originate, such that these can develop also to the contralateral side. Finally, the increase in risk of cerebral astrocytomas and acoustic neuromas, in particular ipsilateral, is higher in the subgroup that started using MPs at an age $<20$ years, even if the $95 \%$ CIs are very broad, owing to the still-limited number of subjects being studied (Table 1).

It should be stressed that a greater increase in ipsilateral tumours than in total tumours, but absence of increase in contralateral tumours, is precisely what would be expected in the case of MPs having oncogenic action [4,5].

A detailed analysis of the data from Hardell's seven most recent studies [7-10], including the pooled analyses [1-3], shows that (see additional file 1): 
Table 1 Results from the case-control studies by Hardell.

\begin{tabular}{|c|c|c|c|c|c|c|}
\hline tumours & \multicolumn{2}{|c|}{ analogue } & \multicolumn{2}{|c|}{ digital } & \multicolumn{2}{|c|}{ cordless } \\
\hline brain malign & (82/84): & $2.4 ; 1.6-3.4$ & (19/18): & $2.8 ; 1.4-5.7$ & (33/45): & 1,$8 ; 1,1-3.0$ \\
\hline only astrocytomas I-IV & (59/84): & $2.7 ; 1.8-4.2$ & (15/18): & $3.8 ; 1.8-8.1$ & (23/45): & $2.2 ; 1.3-3.9$ \\
\hline brain benign & (57/84): & $1.8 ; 1.2-2.6$ & (13/18): & $1.6 ; 0.8-3.5$ & (28/45): & $1.4 ; 0.8-2.3$ \\
\hline only meningiomas & (34/84): & $1.6 ; 1.02-2.5$ & (8/18): & $1.3 ; 0.5-3.2$ & (23/45): & $1.6 ; 0.9-2.8$ \\
\hline acoustic neuromas & (19/84): & $3.1 ; 1.7-5.7$ & (1/18): & $0.6 ; 0.1-5.0$ & (4/45): & $1.0 ; 0.3-2.9$ \\
\hline
\end{tabular}

Idem, but also as a function of head tumour laterality [3] ( $\geq 10$-year latency)

\begin{tabular}{|c|c|c|c|c|c|c|c|}
\hline \multirow{3}{*}{$\begin{array}{c}\text { tumours } \\
\text { astrocytomas } \\
\prime \prime\end{array}$} & \multirow{2}{*}{$\frac{\text { MP type }}{\text { analogue }+ \text { digital }}$} & \multicolumn{2}{|c|}{ all } & \multicolumn{2}{|c|}{ ipsilateral } & \multicolumn{2}{|c|}{ contralateral } \\
\hline & & (78/99): & $2.7 ; 1.8-3.9$ & (50/45): & $3.3 ; 2.0-5.4$ & (26/29): & $\underline{2,8 ; 1,5-5.1}$ \\
\hline & cordless & (28/45): & $2.5 ; 1.4-4.4$ & (19/15): & $5.0 ; 2.3-11.0$ & (8/20): & $1.4 ; 0.6-3.5$ \\
\hline others malign & analogue + digital & (8/99): & $\underline{3.2 ; 1.2-8.8}$ & (4/45): & $\underline{4.1 ; 1.03-16.0}$ & (1/29): & $1.7 ; 0.2-15.0$ \\
\hline$"$ & cordless & (1/45): & $1.1 ; 0.1-10.0$ & - & not analysed & (1/20): & $3.9 ; 0.3-44.0$ \\
\hline neuromas & analogue + digital & (20/99): & $2.9 ; 1.6-5,5$ & (13/45): & 3.0: $1.4-6.2$ & (6/29): & $2.4 ; 0.9-6.3$ \\
\hline$"$ & cordless & (4/45): & $1.3 ; 0.4-3.8$ & (3/15): & $2.3 ; 0.6-8.8$ & (1/20): & $0.5 ; 0.1-4.0$ \\
\hline meningiomas & analogue + digital & (38/99): & $1.5 ; 0.98-2.4$ & (18/45): & $1.6 ; 0.9-2.9$ & (12/29): & $1.6 ; 0.7-3.3$ \\
\hline$"$ & cordless & (23/45): & $1.8 ; 1.01-3.2$ & (11/15): & $3.0 ; 1.3-7.2$ & (7/20): & $1.1 ; 0.5-2.9$ \\
\hline
\end{tabular}

Idem, only individuals who started using MPs $<20$-year old ( $\geq 1$-year latency) $[3,16]$

\begin{tabular}{cccccrrr}
\hline tumours & MP type & \multicolumn{2}{c}{ all } & \multicolumn{2}{c}{ ipsilateral } & \multicolumn{1}{c}{ contralateral } \\
\hline astrocytomas & analogue + digital & $(15 / 14):$ & $\underline{5.2 ; 2.2-12.0}$ & $(8 / 5):$ & $\underline{7.8 ; 2.2-28.0}$ & $(2 / 4):$ & $2.2 ; 0.4-13.0$ \\
$"$ & cordless & $(14 / 16):$ & $\underline{4.4 ; 1.9-10.0}$ & $(9 / 6):$ & $\underline{7.9 ; 2.5-25.0}$ & $(1 / 4):$ & $1.1 ; 0.1-10.0$ \\
neuromas & analogue + digital & $(5 / 14):$ & $\underline{5.0 ; 1.5-16.0}$ & $(3 / 5):$ & $\underline{6.8 ; 1.4-34.0}$ & $(1 / 4):$ & $2.4 ; 0.2-24.0$ \\
$"$ & cordless & $(1 / 16):$ & $0.7 ; 0.1-5.9$ & $(1 / 6):$ & $1.7 ; 0.2-16.0$ & - & not analysed \\
\hline
\end{tabular}

Results of the pooled analyses by Hardell [1-3] on the risk of overall head tumours in exposed subjects compared to that of non-MP-users, as a function of the use of different MP types, (no. of cases and controls with $\geq 10$-year use or latency): OR; $95 \% \mathrm{Cl}$.

$95 \%$ s.s. data.

- the percentage participation in the epidemiological study is always very high (84-91\%) for both cases and controls;

- the percentages of people exposed are sizeable (mean $=60 \%$, but - in a few studies - up to $70-80 \%)$ for both cases and controls;

- MP use is significant: 194 cases used MPs for more than 1000 hours, and 85 for more than 2000 hours, for at least 10 years (i.e. from > 16 to just $>32 \mathrm{~min} /$ day);

- the percentages of cases and controls exposed for at least 10 years are $18 \%$ and $13 \%$ of the total number of exposed cases and controls;

- of the total OR values reported in the above studies, over $90 \%$ are $>1,37 \%$ of which are s.s., and the probability of this highly asymmetrical distribution of OR values being due to chance is almost zero (Figure 1A). This pattern indicates that the results are not due to errors or conditioning in the protocol Hardell used, since in other reports regarding other types of tumour (salivary glands [11] and testicles [12]) in MP users due to the very limited number of those exposed for at least 10 years - no s.s. risk increase is found, nor is there any clear prevalence of OR values $>1$. Only for non-Hodgkin lymphomas [13] a s.s. risk increase is found and the distribution of OR values is shifted towards values $>1(73 \%)$, with low probability of this being due to chance (Figure 1A);

- the increased risk in MP users is not limited to gliomas, meningiomas and acoustic neuromas, but involves also other types of head tumour -low grade and high grade astrocytomas, oligodendrogliomas, medulloblastomas, ependimomas, and other/mixed malignant tumours; pituitary adenomas and other/mixed benign brain tumours - which are considered separately [3].

In the Hardell group studies [1-3,7-10,14] a dose/ response relationship and thus the existence of a causeeffect relationship are documented by the fact that:

- the risk of developing tumours is prevalent, if not exclusive, on the head side habitually exposed to MP radiation (ipsilateral);

- the trend for increase in OR as a function of time of MP use is s.s.;

- the risk is higher in rural areas [15], where the signal required for optimal use of cellular phones is often very limited owing to the low number of base-stations, and the compensatory emission of the cell-phone battery is particularly high (up to $80 \mathrm{~V} / \mathrm{m}$ or more) compared with urban areas where the signal is almost always 


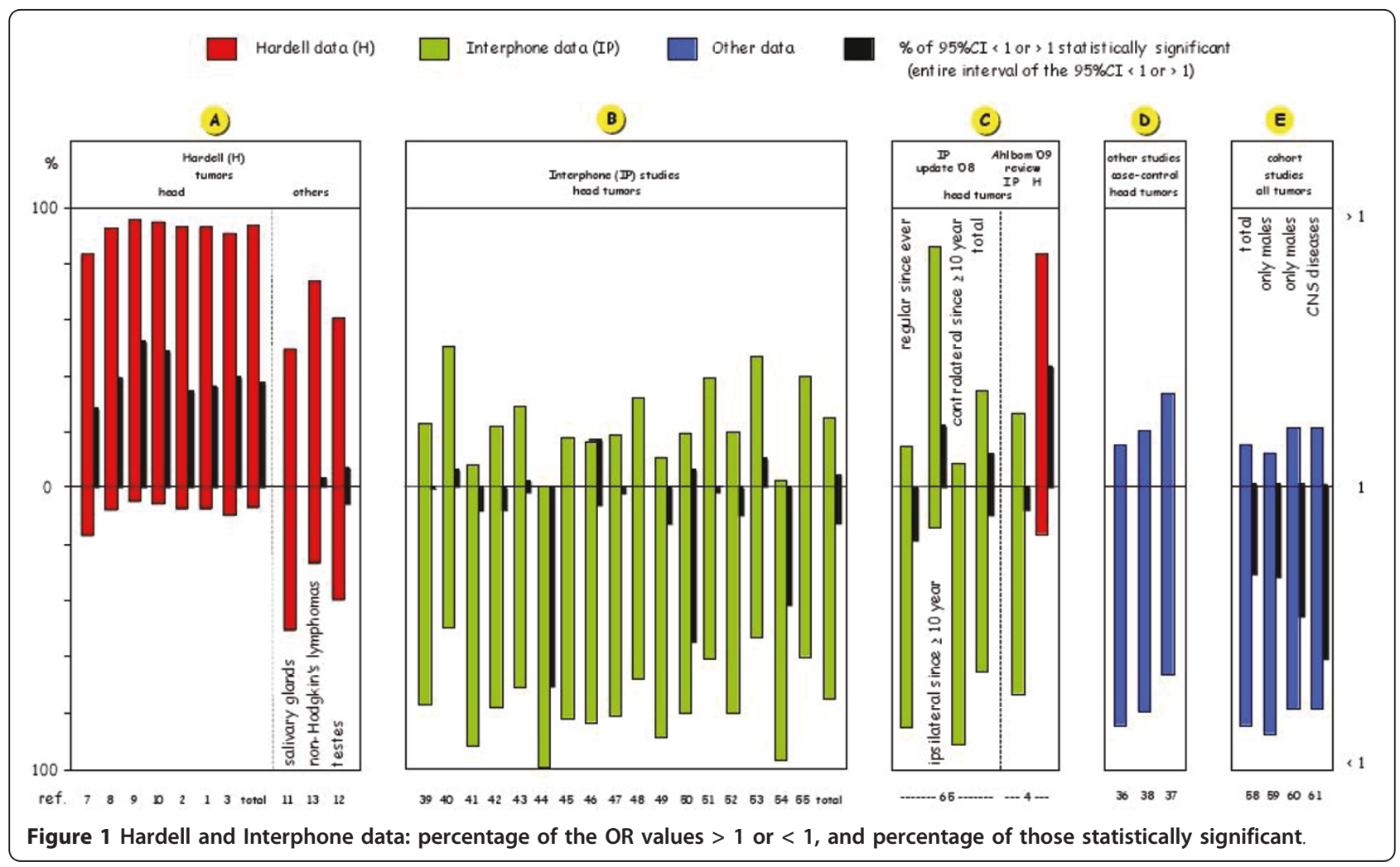

optimal, and the battery emission is a minimum $(1 \mathrm{~V} / \mathrm{m}$ or even less);

- the combined use of various types of MP raises the risk of developing head tumours;

- the risk of head tumour is higher in those starting MP use when aged below 20 years $[3,16]$ (see also Table $1)$.

The biological plausibility of the oncogenic action of the EM radiation emitted by the MPs is supported by a considerable amount of experimental data [17-19]. This radiation, in fact, can produce a variety of effects able to cause or contribute to the neoplastic cell transformation:

- genetic alterations (DNA damage, chromosomal aberrations, micronuclei, sister-chromatid exchanges and gene mutations) in cells irradiated in vitro (including germinal and cerebral cells) [20,21]; in animals exposed in the laboratory $[22,23]$ or natural environment [24], and in MP users [25];

- induction of DNA reparative synthesis and alterations in transcription of DNA, activation of oncogenes and other epigenetic effects [26,27];

- alteration of the blood-brain barrier permeability and brain neuron damage $[28,29]$;

- induction of heat-shock proteins and apoptosis that stress living cells [30,31];

- reduction of melatonin synthesis and activation of Fenton's reaction which increase the concentration of free radicals and peroxides able to damage the DNA [20,32];

- alteration of functionality, count and form of sperms in MP users whose phone stays on and in their trouser pockets during the call $[33,34]$.

It should be noticed that many studies on biological effects of MP use are negative, but for the major part were conditioned having been funded by the cell-phone industry [35] (see Discussion).

\section{MPs and head tumours: negative data}

Between 2000 and 2002 three case-control studies were published - two were funded by MP companies [36,37], while in one no information was given about how the study was funded [38]. The findings indicated no increase in risk of brain or acoustic nerve tumour associated with MP use. However, there was complete absence of subjects exposed for at least 10 years, and the maximum latency period was only 4-5 years (see additional file 2).

On this basis, it is small wonder that there is a complete absence of increase in brain or acoustic tumour risk; quite the contrary: most OR values (67-85\% of 122 total ORs $\neq 1$ ) were $<1$, and the probability of this being chance is very low or almost zero (Figure 1D).

Since 2004, 17 case-control epidemiological studies have been published under the Interphone project 
launched by the International Agency for Research on Cancer (IARC) in 2000 [39-55], and overall are considered to lack any evidence for increase in head tumours in MP users. However, examination of all the above "negative" studies shows that there are bias, confounding factors, and errors in the methodological approach and the data processing and presentation. These factors include (see additional file 3):

- the low participation of cases or controls: $\leq 50 \%$ $[43,44,46,50,54], \leq 60 \%[45,52,55], \leq 70 \%$ [39,42,47-49,53], not even given [37];

- the low percentages of exposed cases or controls: $\leq$ $30 \%$ [36-38], $\leq 40 \%[47,52], \leq 50 \%[39,42,49,54], \leq 60 \%$ $[40,41,43,45,46,48,50,51,53,55]$, not even given [44];

- the low percentages of cases or controls exposed for $\geq 10$ years: $0 \%[36-38,45,49,52,53], \leq 5 \%[39,47,51,55], \leq$ $10 \%[40-42,46,48]$, not even given [44];

- the inadequate definition for "normal use of cell phones" as "at least 1 phone call per week, for at least 6 months". Therefore, if a risk exists, it is "diluted" because of the dominance, in the examined sample, of subjects exposed too little: the average daily use of MPs in subjects considered "exposed" by Interphone is just 2-5 minutes per day, very scarcely representative of the intensive use made of cellphones today;

- the failure to include cordless users who, although exposed, are included among the non-exposed. The Interphone authors justify the exclusion of cordless users through the postulation that the intensity of the EM emission of this type of MP should be irrelevant and in any case much lower than emissions from cell phones, but in fact quite the reverse is true $[1-3,9,10,56]$, to the extent that significant increases in the incidence of malign and benign brain tumours are found by Hardell also in those using only cordless phones (Table 1).

- the relative prevalence in controls exposed over the non-exposed subjects which is due to the fact that, there being no blind protocol, the subjects interviewed knew what was the purpose of the study. Therefore, MP users willingly elect to participate in the study, aware of its goals, while non-users tend to decline. This "selection bias" is recognized by the Interphone authors themselves, but in their view it does not cause reduction in OR of more than $10 \%$ [44,57], which is true for the overall Interphone data, but in some studies this bias alone can result in a more significant reduction in OR assessment: $\geq 15 \%[45,55], \geq 25 \%[39,41,42], \geq 30 \%$ $[37,38,52,54], \geq 50 \%$ [36] (see additional file 4).

In the negative cohort studies [58-61], where exposure is based simply on the fact that subjects work for an industry that produces MPs or are mobile telephony company subscribers (i.e. without the need to question participants), and where the illness/mortality incidence data estimate is based on linkage of data from people exposed with data from national tumour registers, there is an overabundance of data showing a reduced risk of those exposed - in all subjects $[58,61]$ or only in males $[59,60]$ - often s.s. and with very little probability of being chance (Figure 1E, see additional file 5). In these studies the s.s. reduction in risk even concerns organs that most certainly cannot be irradiated during the calls, in particular lung, stomach, liver and pancreas, and also the mortality from all causes, cardiac problems, liver cirrhosis, and car accidents. Clearly, the above "healthy worker effect" is due to systematic methodological errors and bias, e.g. the low prevalence of long exposures or latencies or the inadequate definition of cellphone use.

In the negative case-control studies [36-55] the combination of all the above factors leads to strong underestimation of the risk, and together act such that the majority of OR values are $<1$, often s.s. (Figure 1B):

- in the 17 Interphone studies, out of 1084 OR values different from $1,76 \%$ are $<1$ and only $24 \%$ are $>1$ :

- the prevalence of OR values $<1$ is extremely unusual: $=100 \%[44], \geq 90 \%[41,54], \geq 80 \%[45-47,49,52], \geq$ $70 \%[39,42], \geq 60 \%[43,48,51,55]$;

- the probability of this asymmetric distribution of OR being chance in 6 of these studies is low $[39,42-44,48,51]$, while in another $5[41,46,47,49,54]$, as in the overall data, it is practically zero;

- Lloyd-Morgan [62] applied a probability test to a distribution identical to that above, obtained by examining a lower number of OR values from 11 of the Interphone studies $76 \%$ OR $<1$ and $24 \%$ OR $>1$ ), and found the probability of this being chance to be $6.2 \times 10^{-20}$;

- even more extraordinary, the OR values in 4 studies fall off with increased duration of exposure to MPs and/ or latency time $[36,39,48,52]$.

Discarding the idea of this being due to a protective effect from head tumour risk effected by MP use (not supported by experimental data - indeed, not even the Interphone authors support it), the only explanation can be found from a strong reduction in the assessment of risk resulting from the methodological errors present in the Interphone protocol.

The Interphone researchers themselves have published various studies on the methodological bias and flaws present in their work $[44,57,63]$. Most of the errors are attributed to the fact that the exposure is assessed on the basis of the data self-reported by participants in the case-control study ("recall errors"): in particular, it has been claimed that the increased risks reported in some studies (Table 2) could be due to cases blaming MPs as the cause of the disease. However, recently Hardell published the results of a case-control study on mortality (not incidence) due to malignant brain tumours in 
Table 2 Increased OR values in the Interphone studies on relationships between MP use and head tumours

\begin{tabular}{|c|c|c|c|c|c|c|c|c|c|}
\hline \multirow{3}{*}{$\begin{array}{l}\text { Author (tumour type) } \\
\text { Lonn et al. } \\
\text { (acoustic neuromas) }\end{array}$} & \multirow{2}{*}{$\begin{array}{l}\text { year } \\
2004\end{array}$} & \multirow{2}{*}{$\begin{array}{l}\text { ref. } \\
40\end{array}$} & \multirow{2}{*}{$\begin{array}{l}\text { years MP use } \\
\qquad \text { since } \geq 10\end{array}$} & \multicolumn{2}{|c|}{$\begin{array}{c}\text { total tumours cases/ } \\
\text { controls and OR } \\
(95 \% \mathrm{Cl})\end{array}$} & \multicolumn{2}{|c|}{$\begin{array}{c}\text { ipsilateral tumours } \\
\text { cases/controls and OR } \\
(95 \% \mathrm{Cl})\end{array}$} & \multicolumn{2}{|c|}{$\begin{array}{c}\text { contralateral tumours } \\
\text { cases/controls and OR } \\
(95 \% \mathrm{Cl})\end{array}$} \\
\hline & & & & $14 / 29$ & $1.9(0.9-4.1)$ & $12 / 15$ & $3.9(1.6-9.5)$ & $4 / 17$ & $0.8(0.2-2.9)$ \\
\hline & & & for $\geq 10$ & $11 / 26$ & $1.6(0.7-3.6)$ & $9 / 12$ & $3.1(1.2-8.4)$ & $4 / 16$ & $0.8(0.2-3.1)$ \\
\hline Schoemaker et al. 2005 & & 43 & since $\geq 10$ & $47 / 212$ & $1.0(0.7-1.5)$ & $31 / 124$ & $1.3(0.8-2.0)$ & $20 / 105$ & $1.0(0.6-1.7)$ \\
\hline (acoustic neuromas) & & & for $\geq 10$ & $31 / 131$ & $1.1(0.7-1.8)$ & $23 / 72$ & $1.8(1.1-3.1)$ & $12 / 73$ & $0.9(0.5-1.8)$ \\
\hline Lonn et al. & 2005 & 41 & since $\geq 10$ & $25 / 38$ & $0.9(0.5-1.5)$ & $15 / 18$ & $1.6(0.8-3.4)$ & $11 / 25$ & $0.7(0.3-1.5)$ \\
\hline (gliomas) & & & for $\geq 10$ & $22 / 33$ & $0.9(0.5-1.6)$ & $14 / 15$ & $1.8(0.8-3.9)$ & $9 / 23$ & $0.6(0.3-1.4)$ \\
\hline \multirow[t]{2}{*}{ (meningiomas) } & & & since $\geq 10$ & $12 / 36$ & $0.9(0.4-1.9)$ & $5 / 18$ & $1.3(0.5-3.9)$ & $3 / 22$ & $0.5(0.1-1.7)$ \\
\hline & & & for $\geq 10$ & $8 / 32$ & $0.7(0.3-1.6)$ & $4 / 15$ & $1.4(0.4-4.4)$ & $3 / 23$ & $0.5(0.1-1.8)$ \\
\hline Hepworth et al. & 2006 & 46 & since $\geq 10$ & $66 / 112$ & $0.9(0.6-1.3)$ & & & & \\
\hline \multirow[t]{2}{*}{ (gliomas) } & & & for $\geq 10$ & $48 / 67$ & $1.14(0.74-1.73)$ & & & & \\
\hline & & & regular use & & & $278 / 486$ & $1.24(1.02-1.52)$ & 199/491 & $0.75(0.61-0.93)$ \\
\hline $\begin{array}{l}\text { Schuz et al. } \\
\text { (gliomas) }\end{array}$ & 2006 & 47 & females only $\geq 0.5$ & $30 / 38$ & $1.96(1.1-3.5)$ & & & & \\
\hline Lonn et al. & 2006 & 48 & since $\geq 10$ & $7 / 15$ & $1.4(0.5-3.9)$ & $6 / 9$ & $2.6(0.9-7.9)$ & $1 / 9$ & $0.3(0.0-2.3)$ \\
\hline (parotid gland tumours) & & & for $\geq 10$ & $5 / 13$ & $1.1(0.4-3.6)$ & $4 / 8$ & $2.0(0.5-7.0)$ & $1 / 8$ & $0.3(0.0-2.6)$ \\
\hline Klaeboe et al. & 2007 & 49 & since $\geq 6$ & $70 / 73$ & $0.8(0.5-1.2)$ & $39 / 37$ & $1.3(0.8-2.1)$ & $32 / 42$ & $0.8(0.5-1.4)$ \\
\hline (gliomas) & & & for $\geq 6$ & $55 / 61$ & $0.7(0.4-1.2)$ & $30 / 30$ & $1.2(0.7-2.1)$ & $27 / 34$ & $0.9(0.5-1.5)$ \\
\hline Lahkola et al. & 2007 & 50 & since $\geq 10$ & $143 / 220$ & $0.95(0.74-1.23)$ & $77 / 117$ & $1.39(1.01-1.92)$ & $67 / 121$ & $0.98(0.71-1.37)$ \\
\hline (gliomas) & & & for $\geq 10$ & $88 / 134$ & $0.94(0.69-1.78)$ & $43 / 74$ & $1.14(0.76-1.72)$ & $41 / 71$ & $1.01(0.67-1.53)$ \\
\hline Lahkola et al. & 2008 & 54 & since $\geq 10$ & $73 / 212$ & $0.91(0.67-1.25)$ & $33 / 113$ & $1.05(0.67-1.65)$ & $24 / 117$ & $0.62(0.38-1.03)$ \\
\hline (meningiomas) & & & for $\geq 10$ & $42 / 130$ & $0.85(0.57-1.26)$ & $21 / 73$ & $0.99(0.57-1.73)$ & $13 / 68$ & $0.64(0.33-1.23)$ \\
\hline $\begin{array}{l}\text { Interphone } \\
\text { (gliomas) }\end{array}$ & 2010 & 72 & $\geq 1640$ calls & $160 / 113$ & $1.82(1.15-2.89)$ & $100 / 62$ & $1.96(1.22-3.16)$ & $39 / 31$ & $1.25(0.64-2.42)$ \\
\hline Sadetzki et al. & 2008 & 53 & > 5479 calls & $86 / 157$ & $1.13(0.79-1.61)$ & $121 / 159$ & $1.58(1.11-2.24)$ & $46 / 135$ & $0.78(0.51-1.19)$ \\
\hline \multirow[t]{2}{*}{ (parotid gland tumours) } & & & $>266.3$ hours & $80 / 155$ & $1.03(0.72-1.47)$ & $115 / 158$ & $1.49(1.05-2.13)$ & $48 / 129$ & $0.84(0.55-1.28)$ \\
\hline & & & $>5479$ calls < 5 -year latency & $47 / 82$ & $1.16(0.74-1.82)$ & $35 / 40$ & $1.80(1.05-3.10)$ & $12 / 41$ & $0.63(0.31-1.30)$ \\
\hline$"$ & & & > 5479 calls >5-year latency & $120 / 215$ & $1.08(0.77-1.50)$ & $86 / 119$ & $1.50(1.03-2.20)$ & $34 / 94$ & $0.84(0.52-1.34)$ \\
\hline \multicolumn{2}{|c|}{ only regular users } & & > 5479 calls & $86 / 157$ & $1.48(1.05-2.10)$ & & & & \\
\hline \multirow[t]{6}{*}{ " } & & & > 18997 calls & $81 / 140$ & $1.51(1.05-2.17)$ & & & & \\
\hline & & & > 1035 cumulative calls & $83 / 134$ & $1.50(1.04-2.16)$ & & & & \\
\hline & & & $\geq 18997$ calls, urban areas & 49/99 & $\overline{1.00(0.65-1.55)}$ & & & & \\
\hline & & & "rural areas & $32 / 41$ & $1.81(1.04-3.14)$ & & & & \\
\hline & & & $\geq 1035$ hours, urban areas & $51 / 96$ & $\overline{1.02(0.67-1.58)}$ & & & & \\
\hline & & & "rural areas & $32 / 38$ & $1.96(1.11-3.44)$ & & & & \\
\hline
\end{tabular}

$95 \%$ s.s. data.

subjects who had used MPs and died before the interview could be performed, and found that use of analogue or digital cell-phones gave a s.s. increased risk, highest in the $>10$ year latency group $(\mathrm{OR}=2.4 ; 95 \% \mathrm{CI}$ = 1.4-4.1), increasing with cumulative number of lifetime hours of cellular use and being highest in the > $2000 \mathrm{~h}$ group $(\mathrm{OR}=3.4 ; 95 \% \mathrm{CI}=1.6-7.1)$ [64].

\section{Hardell versus Interphone}

The low number of cases with $\geq 10$ years latency in the above negative studies is confirmed by data given in the last Interphone Study Results update [65]:

- only $54 \%$ of overall cases with "regular since ever use" ( $\geq 1$ call/week for $\geq 6$ months);
- only $5 \%$ of overall cases actually exposed for $\geq 10$ years;

- only $2 \%$ of overall ipsilateral actually exposed for $\geq$ 10 years;

- while OR $<1$ predominate in data referring to "regular use" of cell-phones (85\%, of which $22 \%$ s.s.), the OR distribution clearly shifts towards values $>1$ for only ipsilateral tumours with $\geq 10$-years of cellular use or latency ( $86 \%$, of which $25 \%$ s.s.), with the percentage of s.s. OR $>1$ decreasing to $12 \%$ for total tumours and falling to $0 \%$ for contralateral tumours (Figure $1 \mathrm{C}$, see additional file 6).

Moreover, in some of the Interphone studies s.s. increases in risk for ipsilateral tumours are quite 
common in people having used MPs since or for $\geq 10$ years, and - more generally - even when there is no significant evidence of risk, a clear increase in OR values is often seen considering the figure for ipsilateral rather than total tumours, while there is a net fall for just contralateral tumours (Table 2). Taking into consideration the systematic underestimation of OR values in the Interphone studies, this is a clear indicator of probable carcinogenic risk.

The meta-analysis of Ahlbom [4] includes some of the US studies [36,37] and some of Hardell's earlier data (1999, 2001, 2002, not quoted in the present review) on risks of glioma, clearly lacking cases with $\geq 10$-year latency time. Moreover it reports from Hardell [8] only data selectively chosen for subjects with "ever/never use" (> 5 year latency) but not, among those with 10 years since first use, the much more significant increases of risks, although these are clearly indicated in Hardell's paper analogue, digital, and cordless phone use. This meta-analysis shows data overall lacking any indication of carcinogenic risk, but underlines the absolute incompatibility between the two data sources: $83 \%$ of Hardell's risk data $(\mathrm{OR})$ are $>1,43 \%$ of which s.s., while the Interphone data are largely $<1(73 \%), 11 \%$ of which s.s. (Figure 1C, see additional file 6).

In contrast, the meta-analyses of Hardell $[14,66]$, Kundi [5], and Khurana [67] including the literature data on ipsilateral head tumours in people having used MPs since or for $\geq 10$ years - and so also part of the Interphone data $[40,43,46,50]$ - show large and s.s. increases (100\%) for the risk of ipsilateral astrocytomas with high level of malignancy, and sizable and s.s. increases (50-140\%) for the risk of acoustic neuromas (Table 3). These increases are smaller than those found by Hardell in the pooled analyses of his data alone (Table 1), being "diluted" with the Interphone data corresponding to the requirements indicated above. Indeed, by separating the overall OR data of these meta-analyses according to their source $[5,14,66,68]$, only Hardell's OR data are systematically $>1$ (90-100\%), $50-90 \%$ of which are s.s., whereas Interphone data include $50-70 \%$ of OR $<1$, a proportion of which (up to $>20 \%$ ) are s.s. Moreover, when only ipsilateral data are considered [67], even $100 \%$ of the Interphone OR are > 1, 29\% of which are s.s. (Figure 2A, see additional file 7).

Also our meta-analyses of the literature data (Figures $3,4,5$ ), limited to subjects with ipsilateral tumours and MP latency $\geq 10$ years (see additional file 8 ), show sizable and s.s. increases in risk of only ipsilateral acoustic neuromas (over 70\%) and astrocytomas (almost 60\%) compared to subjects not exposed to MP radiation, but it should be noted that the overall figure for these metaanalyses is strongly conditioned by the inclusion of the Interphone data. The results of our meta-analyses confirm the need to identify the head tumour localisation relative to the habitual head side of MP use, which is exposed to $97-99 \%$ of the radiation; therefore, the failure to identify the ipsilaterality of tumours adds an additional "dilution factor" to the risk evaluation.

Instead, the meta-analyses by Lloyd-Morgan [62] and Kan [69], limited to a subset of the Interphone data and without analysing tumour laterality or restricting reference to cases with MP use or latency $\geq 10$ years, show a prevalence $(75 \%)$ of OR values $<1$, partly $(33 \%)$ s.s. for the Interphone data, and an equal split of values $<1$ and $>1$ for Hardell's data, $100 \%$ of those $>1$ being s.s (see additional file 7). The same pattern is shown by Lahkola meta-analysis [70], based on a "targeted" choice of data from the first US studies [36-38] and even from a cohort study [59], as well as from certain Interphone [41-43] and Hardell studies [8,9] (these latter data for the main part selectively chosen). In fact, Lahkola [70], besides including Hardell's earlier data (1999, 2002, not quoted in the present review) clearly lacking cases with $\geq 10$-year latency time, calculated "through the pooling of different exposures or tumor categories" moderate

Table 3 Results of the meta-analyses by Hardell, Kundi, and Kurana including Interphone data ( $\geq 10$ year latency)

\begin{tabular}{|c|c|c|c|c|c|c|c|}
\hline \multicolumn{2}{|l|}{ tumours } & \multicolumn{2}{|c|}{ all } & \multicolumn{2}{|c|}{ ipsilateral } & \multicolumn{2}{|c|}{ contralateral } \\
\hline astrocytomas I-IV & ref. 14,66 & (338/511): & $1.2 ; 0.8-1.9$ & (n.s.): & $2.0 ; 1.2-3.4$ & (n.s.): & $1.1 ; 0.6-2.0$ \\
\hline$"$ & 5 & (233/330): & $1.5 ; 1.2-1.8$ & (n.s.): & $1.9 ; 1.4-2.4$ & $-:$ & not analyzed \\
\hline$"$ & 67 & (233/330): & $1.3 ; 1.1-1.6$ & (118/145): & $1.9 ; 1.4-2.4$ & (93/150): & $1.2 ; 0.9-1.7$ \\
\hline neuromas & ref. 14,66 & (83/355): & $1.3 ; 0.6-2.8$ & (53/167): & $2.4 ; 1.1-5.3$ & (30/151): & $1.2 ; 0.7-2.2$ \\
\hline$" \prime$ & 5 & (67/311): & $1.3 ; 0.95-1.9$ & (n.s.): & $1.5 ; 1.1-2.5$ & $-:$ & not analyzed \\
\hline$"$ & 67 & (67/311): & $1.3 ; 0.97-1.9$ & (41/152): & $1.6 ; 1.1-2.4$ & (26/134): & $1.2 ; 0.4-1.03$ \\
\hline meningiomas & ref. 14,66 & (61/152): & $1.3 ; 0.9-1.8$ & (20/46): & $1.7 ; 0.99-3.1$ & $(15 / 52):$ & $1.0 ; 0.3-3.1$ \\
\hline$"$ & 5 & (116/320): & $1.1 ; 0.8-1.4$ & (n.s.): & $1.3 ; 0.9-1.9$ & $-:$ & not analyzed \\
\hline & 67 & (116/320): & $0.9 ; 0.7-1.3$ & (48/141): & $1.1 ; 0.7-1.7$ & (36/164): & $0.6 ; 0.4-1.03$ \\
\hline
\end{tabular}

95\% s.s. data; n.s. $=$ not specified. 


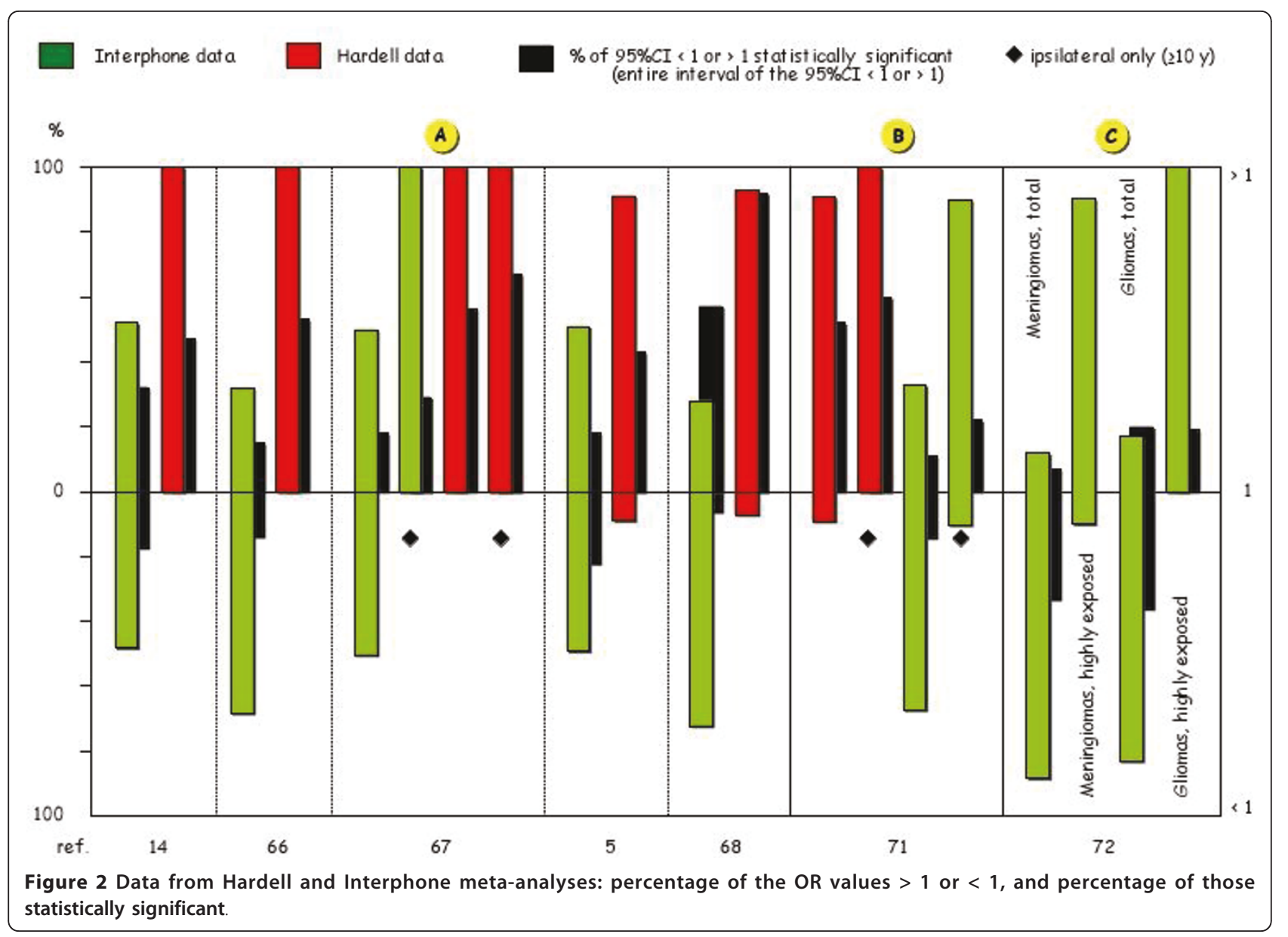

risks for $>5$-year latency of neuromas plus meningiomas and of malign intracranial tumours from Hardell $[8,9]$, whereas the original Hardell's much higher risks of meningiomas, neuromas, and malign brain tumours for $>10$ year latency were not included in Lahkola's metaanalysis.

The reasons underlying the discrepancy between Hardell's positive data and the negative Interphone findings are seen clearly by close examination of the latest articles from the two groups. Hardell [71] carried out a new meta-analysis, which took into account the Interphone data as well as his own: while the data overall do not show any increase in head tumour risk in MP users, limiting the meta-analysis to just ipsilateral tumours in individuals with $\geq 10$-year latency, a s.s. increase in risk is found for gliomas $(\mathrm{OR}=1.9 ; 95 \% \mathrm{CI}=1.4-2.4)$ and for acoustic neuromas $(\mathrm{OR}=1.6 ; 95 \% \mathrm{CI}=1.1-2.4)$. Furthermore, while in Hardell's data $>90 \%$ of OR values are $>1$, for the main part $(>50 \%)$ s.s., this is the case for the Interphone data only when the analysis is limited to ipsilateral tumours in individuals with $\geq 10$-year latency: $90 \%$ of OR values $>1,22 \%$ of which s.s. (Figure $2 \mathrm{~B}$, see additional file 9).
In the first "official" Interphone Study Group [72], considering gliomas and meningiomas, the prevalence of OR values $<1$ is notable (almost $80 \%$ ), over $30 \%$ of these being s.s. (Figure 2C). Obviously, also this study is characterized by the usual bias and flaws:

- the low participation of cases (78\% for meningiomas: range $56-92 \%$; $64 \%$ for gliomas: range $36-92 \%$ ), and especially of controls (53\%: range $42-74 \%$ );

- the low median lifetime cumulative call time: $75 \mathrm{~h}$ for meningiomas (median: $2 \mathrm{~h} / \mathrm{month}$, i.e. $4 \mathrm{~min} /$ day), and $100 \mathrm{~h}$ for gliomas (median: $2.5 \mathrm{~h} /$ month, i.e. $5 \mathrm{~min} /$ day);

- the low percentage of cases with $\geq 10 \mathrm{y}$ since the start of ipsilateral MP use: $3 \%$ of meningiomas, and $6.5 \%$ of gliomas.

However, analysis limited to subjects with "highest cumulative call times" shows a marked prevalence of OR values $>1$ [ $90 \%$ for meningiomas, and $100 \%$ for gliomas (20\% s.s.)] (Figure 2C, see additional file 9). Moreover, given the selection bias due to the underrepresentation of never users among controls, an analysis was carried out with short-term users as controls. In this analysis, the OR values for glioma are almost 


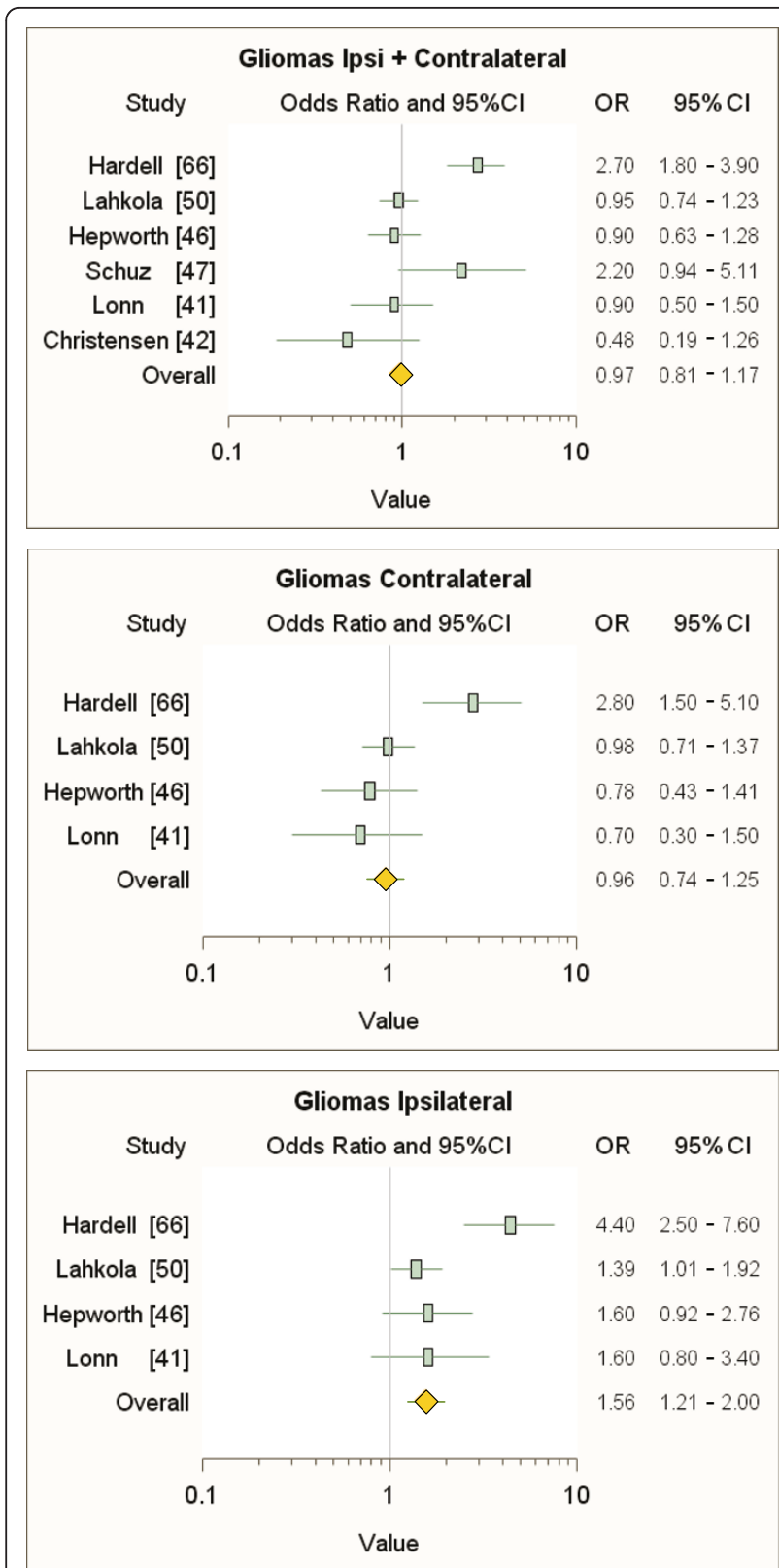

Figure 3 Meta-analyses on data on gliomas after $\geq 10$-year latency

all $>1,30 \%$ of which s.s. with a dose-response relationship, showing that those who used MPs for $\geq 10$ years are twice as likely to develop a brain tumour, especially in the ipsilateral side $(\mathrm{OR}=1.96 ; 95 \% \mathrm{CI}=$ 1.22-3.16) compared to total tumours ( $\mathrm{OR}=1.82$; $95 \%$ $\mathrm{CI}=1.15-2.89)$ and contralateral tumours $(\mathrm{OR}=1.25$; 95\%CI $=0.64-2.42$ ) (Table five of the Interphone text, and Table in its Appendix 2 online), just what is expected in the case of MPs having oncogenic action. This should rule out the possibility of the increase in risk of head tumours in high MP users, and indeed the

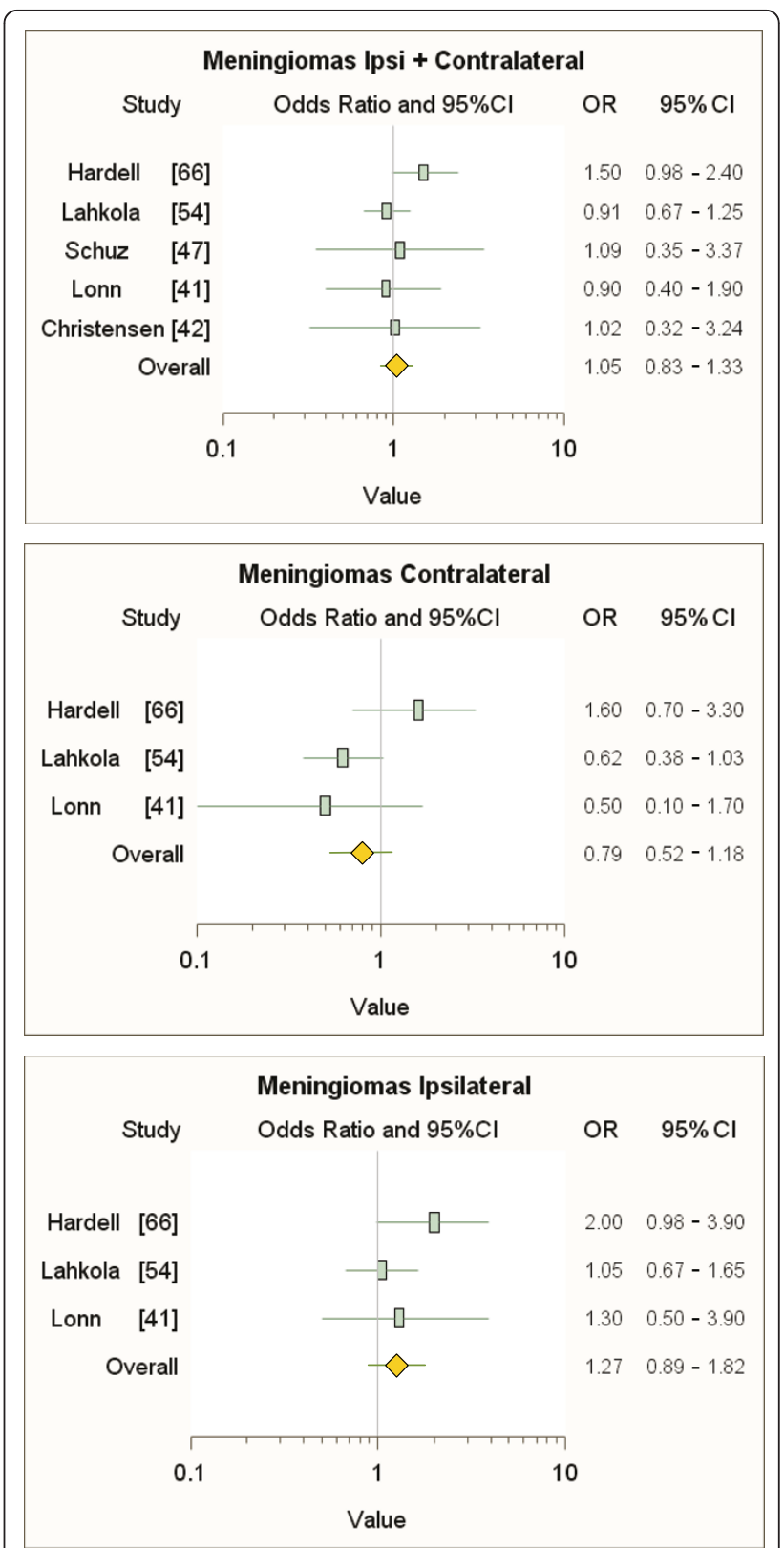

Figure 4 Meta-analyses on data on meningiomas after $\geq 10$ year latency.

increase in gliomas, acoustic neuromas and parotid gland tumours reported in some Interphone studies (Table 2), being due to methodological bias and confounding factors.

The conclusive report from Interphone [72] was accompanied by a commentary [73] whose title is very telling - "Call me on my mobile phone ... or better not? - a look at the Interphone study results", which pointed out some of the chief bias highlighted in the present report. Our analyses strongly reduces the uncertainty of the response to the quoted question: "better not" ! 

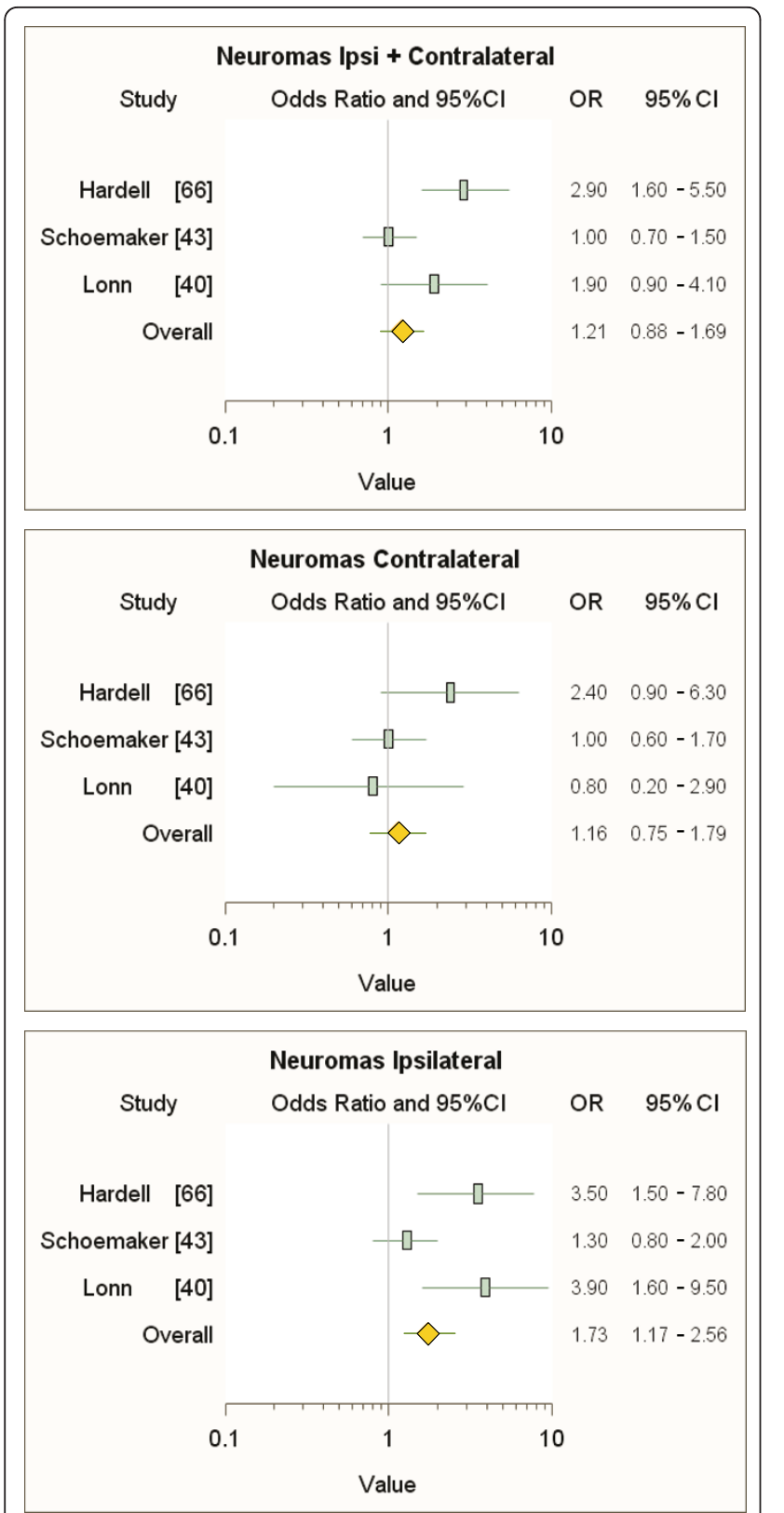

Figure $\mathbf{5}$ Meta-analyses on data on acoustic neuromas after $\geq$ 10-year latency.

And indeed, even some Interphone authors have expressed disagreement with the reassuring interpretation of the Interphone results, which essentially indicates a lack of cause for alarm [72]. In September 2009, before the US Senate [74], Sadetzki defended the validity of her results showing an increase in risk of parotid tumour in strong cell-phone users, particularly in rural areas [53]. Finally, an editorial by Cardis, former Interphone coordinator, and by Sadetzki - also under a highly significant title "Indications of possible braintumour risk in mobilie-phone studies: should we be concerned?" [75] - gives a careful discussion of a selection of Hardell's main papers $[1,2,10]$, noting that these show an increase in cerebral tumour risk in people using MPs for relatively long periods, and recognizes that the Interphone research contains a number of bias that lead to large underestimation of the risk values, among which some of those highlighted in the present report.

On the other hand, the editorial points out a number of observations supporting the risk:

- a $40 \%$ increase risk for glioma in the highest decile of cumulative call time;

- the increase of risk with time since start of use, suggesting a true effect of mobile-phone use;

- the increased risk of tumours in the temporal lobe in the highest decile of cumulative time.

The authors conclude that "the overall balance of the aboved-mentioned arguments suggests the existence of a possible association" between MP exposure and increased head tumour risk.

\section{Discussion}

Previous studies identified a number of study design flaws and bias that give rise to underestimation of the real risk in epidemiological studies, particularly in those funded by industries [76,77]. The present paper, which concerns one of the most presently controversial debate - the possible relationship between MP use and increased risk of head tumours - shows that the negative results produced by studies funded by the cell-phone companies are affected by many biases and flaws, giving rise to a systematic underestimate of the risk. On the contrary, studies producing positive results - without errors and financial conditioning - indicate a cause/ effect relationship supported by biological plausibility.

It must be noticed that the s.s. increase in malignant brain tumour risk repeatedly reported by Hardell among long-term MP users [1-3] is supported by the ageadjusted incidence increase of such tumours in Sweden [78]: during 1970-2007 the annual age-adjusted increase for all brain tumours was $+0.28 \%(95 \% \mathrm{CI}=+0.04$ to + 0.52 ), whereas during 2000-2007 the figure for astrocytomas was $+1.55(95 \% \mathrm{CI}=-0.15$ to +3.27 , and even higher and s.s. in the age group > 19 years $(+2.16$; $95 \%$ $\mathrm{CI}=+0.25$ to 4.10 ). In addition, the s.s. increase in the risk of parotid gland malignant tumours reported by Sadetzky in cell-phone users [53] is supported by the incidence increase of such tumours in Israel [79]: the mean annual incidence of parotid cancers increased 4fold from 1970 (16 cases/year) to 2006 (64 cases/year), whereas the incidence of other salivary gland tumours remained stable. The steepest increase in parotid cancers occurred after 2001, with an average of 37 cases annually before that date, and 61 cases per year 
subsequently; an increase of this magnitude cannot be due to population growth as the population of Israel increased 2.1-fold from 1970 to 2001, but only 1.1-fold from 2001 to 2006 . The above data seem to indicate that, starting from 2000-2001, a new factor capable of increasing the risk of malignant head tumours among MP users began to manifest its effect, which is in accordance with the $\geq 10-15$ years latency reached by cellular and cordless phone users in those years in both Sweden and Israel (see Background).

There are many bias and flaws in the Interphone and similar studies that lie behind the large prevalence of OR values $<1$ in the overall results, giving rise to a systematic underestimate of the risk $[78,80-84]$ whereas the protocol by Hardell producing positive results is without apparent errors or financial conditioning (Table 4), the results indicating a cause-effect relationship supported by biological plausibility [17-34]. A review on health effect of MPs showed that the studies reporting one or more s.s. positive results were funded by public bodies, while studies funded exclusively by industries were seven fold less likely to report at least one such result, and the difference between the two sets of data was highly s.s. [35]. According to the authors "this study indicates that the interpretation of the results from existing and future studies ... should take sponsorship into account".

Likewise, the discrepancy between the positive data of Hardell and the negative data from Interphone is highlighted by the authors that performed a random-effect model meta-analysis of 24 case-control studies [85]. These authors observed a s.s. positive association between MP use and increased head cancer risk in 10 studies ("high-quality studies", including 7 studies by Hardell, only 1 by Interphone, and 2 by other groups), whereas a negative association (i.e. an apparent "protective effect") was observed in 14 studies ("low-quality studies", including 12 by Interphone, and 2 by other groups). Elements in the method used to evaluate the "quality" of the studies were: a) blind or non-blind protocol; b) presence or absence of participation and selection bias of cases and controls; c) relevant or marginal MP exposure; d) adequate or inadequate latency or overall time of MP use; e) scrutiny of tumour laterality; f) funding by independent sources or by cell-phone companies. The authors make the following conclusion: "We feel the need to mention the funding sources for each research group because it is possible that these may have influenced the respective study designs and results".

The Hardell group was supported only by grants from Public Bodies, whereas the Interphone-related studies by the Quality of Life and Management of Living Resources program of the European Union and the International Union Against Cancer; but the latest received funds for those studies from the Mobile Manufacturers Forum and the Global System for Mobile Communication Association [86]. According to the Interphone protocol [86], "the partial funds provided by the above cell-phone Associations to the International Union Against Cancer complement funds from non-commercial sources including the European Union and national local research funding organization", but "provision of funds

Table 4 Errors in negative Interphone studies [4,36-55,65,72], and reliability of positive Hardell studies $[1-3,7-10,64,71,78]$

\begin{tabular}{|c|c|c|}
\hline study, design, methods & negative studies & positive studies \\
\hline Mobile phone use & inadequate: 2-5 min/day & significant: 16-32 min/day \\
\hline Latency time & $<5 \%$ cases with latency $\geq 10 y$ & $>18 \%$ cases with latency $\geq 10 y$ \\
\hline Cordless phone users & considered unexposed & considered exposed \\
\hline Ipsilateral tumour latency & $\geq 10$ y for only $2 \%$ cases & $\geq 10$ y for $>16 \%$ cases \\
\hline Head tumours identified & only gliomas, meningiomas, neuromas, parotid tumours & also other head tumours types \\
\hline Deceased cases & not included & included: proxy interviews \\
\hline Interviews & not blind & always double blind \\
\hline Type of interviews & face-to-face & mailed questionnaires \\
\hline \multirow[t]{2}{*}{ Time of interviews } & cases: during hospitalisation & cases: after hospitalisation \\
\hline & controls: at home & controls: at home \\
\hline Exposure assessment & non blind interview & blind questionnaire \\
\hline Data processing & not stated (not blind?) & Blind \\
\hline Laterality attribution bias & present & Absent \\
\hline Delayed interviews & for controls compared to cases & not delayed \\
\hline Participation & reduced up to $40 \%$ & always near to $90 \%$ \\
\hline Selection & exposed controls prevail & no selection bias \\
\hline Documentation & positive data ignored & no documentation bias \\
\hline Funding & co-funded by MP Companies & funded only by Public Bodies \\
\hline
\end{tabular}


to the Interphone study investigators via the International Union Against Cancer is governed by agreements that guarantee Interphone's complete scientific independence", and "the funders of the Interphone studies do not have access to any results of the studies before their publication. They may, however, be informed, together with representatives of other concerned organizations such as consumer groups, a maximum of seven days before the publication of the results, under strict terms of confidentiality".

In addition to the above funds, several authors participating in the Interphone study received additional funding from their national MP companies $[43,44,47,51,63]$ or by other private companies $[42,59,60]$, such that a substantial portion of the Interphone Study funding came from the cell-phone industry. These additional funds are not specified in the Interphone protocol [86], and the agreements regulating access to the experimental results and the control of their use by the array of national cellphone and other private companies involved are not known. Furthermore, other negative studies quoted in the present article have been supported by the mobile phone industry, for example the two Muscat studies $[36,37]$ (Cellular Industry Telecommunications Association via the Wireless Technology Research) $[19,62]$, the Johansen study [59] (TeleDanmark Mobil, Sonofon and the International Epidemiology Institute, a private company operating as a cell-phone industry adviser), and the Morgan study [58] (Motorola).

Nevertheless, of the authors of the above negative studies, 14 [36,37,39-44,46,50,53,54,58,59] do not make any declaration about conflict of interest, $3[47,48,52]$ state "conflict of interest: none declared" (it is not clear whether this is from the authors or from the editor), while $4[45,49,51,55]$ declare "conflict of interest: none".

Also the European Environment Agency [87], the European Parliament [88], and two recent papers $[89,90]$ have expressed preoccupations about the effects on human health, particularly on that of young people, by the continuous RF exposure produced in public places and at home by wi-fi for internet access and MP use. The European Parliament has also pointed at "the need to evaluate scientific integrity of the authors, in order to forestall possible risks, conflicts of interest or even frauds which tend to arise in a context of growing competition among researchers" [88].

\section{Conclusions}

Our examination of the literature data, together with the results of our and other's meta-analyses, lead to the conclusion that even today the risk of head tumours resulting from MP use is very high. Lloyd-Morgan, while underestimating by $50 \%$ the number of cell users, without considering cordless users and assuming a minimum latency time of 30 years, calculates "there would be about 1900 cellphone-induced brain tumours out of about 50,000 brain tumours diagnosed in 2004, increasing to about 380,000 cell-phone-induced brain tumours within 2019 in the USA alone", which would require "an increase in health costs of an annual US\$ 9.5 billion and the need for a 7-fold increase in number of neurosurgeons". An estimate of the incidence of head tumours must begin with the correct number of cell-phone users ( 5 billion subscriptions worldwide at mid 2010), should also consider the risk to cordless users, and assume at least a doubling of the incidence of head tumours and of acoustic neuromas as documented by Hardell already after a latency of at least 10-15 years.

Most likely, a number of factors raise our concern still further - for example, the latency of head tumour induced by MPs can exceed 30 years; risk is higher in those starting MP use when young and who have not yet accumulated 10 years of latency; there is a continued rise in MP use by youngsters, attracted to new offers from the MP companies (photography, listening to music, videophony, internet, etc.); the data of Hardell on the increase in other types of malign and benign head tumour- besides brain gliomas, astrocytomas, and acoustic neuromas - are for the main part today only indicative. Therefore, today we are evaluating just the tip of an iceberg, and will have to wait one or two decades before its real dimensions come to light. But it is clear that the analysis we have presented already shows a clear increase in tumour risk, and - if it proves even partly founded - the use of MPs could lead to a health crisis of dramatic proportion.

Furthermore, the recent editorial by Cardis and Sadetzky about the conclusive Interphone report states that "There are now more than 4 billion people, including children, using mobile phones. Even a small risk at the individual level could eventually result in a considerable number of tumours and become an important public-health issue. Simple and low-coast measures, such as the use of text messages, hands-free kits and/or the loud-speaker mode of the phone could substantially reduce exposure to the brain from mobile phones. Therefore, until definitive scientific answers are available, the adoption of such precautions, particularly among young people, is advisable".

While recognizing that mobile telephony is an outstanding technology of inestimable value, responsible science must raise awareness of the risks involved.

We thus conclude that already today there is sufficient epidemiological evidence to warrant application of the precautionary principle aimed at:

- setting exposure limits that are precautionary;

- limiting the spread of wireless technology in schools and highly frequented places (libraries, offices, hospital wards); 
- providing accurate information about the risks from exposure to MPs, with low-cost voluntary options ("prudent avoidance") based on the caution in the use of MPs. A 10-point list of simple personal actions designed to substantially reduce the exposure to cell-phone radiation was produced by Viennese Medical Officers in 2006, adopted in the same year by the French Agency on Radiofrequencies http://www.sante-radiofrequences. org, by several study groups [[17-19], also http://www. devradavis.com.

- awareness-raising in schools through a campaign on the use of the various wireless transmission technologies;

- discouraging the use of MPs by minors under 14 years;

- epidemiological monitoring of the possible oncogenic action of home and workplace EM exposures.

\section{Additional material}

Additional file 1: MP use and tumours. Main features of the casecontrol studies by Hardell et al. on the relationships between MP use and brain and acoustic nerve tumours and other types of tumours.

Additional file 2: Features of case-control studies before Interphone. Main features of case-control studies performed before the Interphone project on the relationships betweeen MP use and brain and acoustic nerve tumours.

Additional file 3: Feature of case control studies by Interphone. Main features of the case-control Interphone studies on the relationships between MP use and head tumours.

Additional file 4: Reduction of OR by selection bias. Percent reduction of the $\mathrm{OR}$ estimation due to selection bias of cases and controls.

Additional file 5: MP and CNS tumours in cohort studies. Main features of the cohort studies on the relationships between MP use and tumours or central nervous system (CNS) diseases.

Additional file 6: Data of Interphone update and Ahlbom review. Main features of the Interphone update and the Ahlbom review on the data from case-control studies on the relationships between MP use and head tumours.

Additional file 7: Meta-analyses on MP and head tumours. Main features of the meta-analyses of case-control studies on the relationships between MP use and head tumours.

Additional file 8: Studies included in the meta-analysis. Summary of studies included in the meta-analysis (latency time $\geq 10$ years.

Additional file 9: Risk on MP and head tumours in Hardell and Interphone studies. Risk (OR) distribution in the latest Hardell and Interphone studies on the relationships between MP use and head tumours.

\section{List of Abbreviations}

EM: electromagnetic; IARC: International Agency for Research on Cancer; MP: mobile phone; OR: odds ratio; Cl: confidence interval; s.s.: statistically significant

\section{Acknowledgements}

Financial support from University of Padova - Italy. The authors wish to thank Dr Susan Biggin for valuable suggestions and language/editorial input in preparation of the manuscript.

\section{Author details}

${ }^{1}$ Department of Experimental Biomedical Sciences, Medical School of Padova, Padova, Italy. ${ }^{2}$ Institute of Neuroscience, National Research Council, Padova, Italy. ${ }^{3}$ Local Sanitary Unit, Mantova, Italy. ${ }^{4}$ National Cancer Research Institute (IST), Genova, Italy.

\section{Authors' contributions}

$A G L$ and SG are responsible for the collection and analysis of data, and writing the manuscript. NM performed the meta-analyses. All the Authors contributed to the discussion of data and draw conclusions, and approved the final manuscript.

\section{Competing interests}

The authors declare that they have no competing interests.

Received: 23 February 2011 Accepted: 17 June 2011

Published: 17 June 2011

\section{References}

1. Hardell L, Carlberg M, Hansson-Mild K: Pooled analysis of two case-control studies on the use of cellular and cordless telephones and the risk of benign brain tumours diagnosed during 1997-2003. Int J Oncol 2006, 28:509-518.

2. Hardell L, Carlberg M, Hansson-Mild K: Pooled analysis of two case-control studies on use of cellular and cordless telephones and the risk for malignant brain tumours diagnosed in 1997-2003. Int Arch Occup Environ Health 2006, 79:630-639.

3. Hardell L, Carlberg M: Mobile phones, cordless phones and the risk for brain tumours. Int J Oncol 2009, 35:5-17.

4. Ahlbom A, Feychting M, Green A, Kheifets L, Savitz DA, Swerdlow AJ, ICNIRP: Epidemiologic evidence on mobile phones and tumor risk: A review. Epidemiology 2009, 20:639-652.

5. Kundi M: The controversy about a possible relationship between mobile phone use and cancer. Environ Health Perspect 2009, 117:316-324.

6. Sutton AJ, Abrams KR, Jones DR, Sheldon TA, Song F: Methods for MetaAnalysis in Medical Research John Wiley\&Sons, LTD; 2000.

7. Hardell L, Hansson-Mild K, Carlberg M: Further aspects on cellular and cordless telephones and brain tumours. Int J Oncol 2003, 22:399-407.

8. Hardell L, Carlberg M, Hansson-Mild K: Case-control study on cellular and cordless telephones and the risk for acoustic neuroma or meningioma in patients diagnosed 2000-2003. Neuroepidemiology 2005, 25:120-128.

9. Hardell L, Carlberg M, Hansson-Mild K: Case-control study of the association between the use of cellular and cordless telephones and malignant brain tumors diagnosed during 2000-2003. Environ Res 2006, 100:232-241.

10. Hardell L, Hansson-Mild K, Carlberg M, Soderqvist F: Tumour risk associated with use of cellular telephones or cordless desktop telephones. World J Surg Oncol 2006, 4:74

11. Hardell L, Hallquist A, Hansson-Mild K, Carlberg N, Gertzèn H, Schildt EB, Dahlqvist A: No association between the use of cellular or cordless telephones and salivary gland tumours. Occup Environ Med 2004, 61:675-679.

12. Hardell L, Carlberg M, Ohlson CG, Westberg H, Eriksson M, Hansson-Mild K: Use of cellular and cordless telephones and risk of testicular cancer. Int J Androl 2007, 30:115-122.

13. Hardell $L$, Eriksson M, Carlberg M, Sundstrom C, Hansson-Mild K: Use of cellular or cordless telephones and the risk for non-hodgkin's lymphoma. Int Arch Occup Environ Health 2005, 78:625-632.

14. Hardell L, Carlberg M, Soderqvist F, Hansson-Mild K, Morgan LL: Long-term use of cellular phones and brain tumours: Increased risk associated with use for $>$ or $=10$ years. Occup Environ Med 2007, 64:626-632.

15. Hardell L, Carlberg M, Hansson-Mild K: Use of cellular telephones and brain tumour risk in urban and rural areas. Occup Environ Med 2005, 62:390-394.

16. Hardell L, Hansson-Mild K, Carlberg M, Hallquist A: Cellular and cordless telephone use and the association with brain tumors in different age groups. Arch Environ Health 2004, 59:132-137.

17. Carpenter D, Davanipour Z, Gee D, Hardell L, Johansson O, Lai H, Hansson-Mild K, Sobel E, Xu Z, Chen G: Biolnitiative Report: a rationale for a biologically-based public exposure standard for electromagnetic 
fields (ELF and RF). 2007 [http://www.bioinitiative.org], accessed 22.10.2007.

18. Hardell L, Sage C: Biological effects from electromagnetic field exposure and public exposure standards. Biomed Pharmacother 2008, 62:104-109.

19. Lloyd-Morgan L, Barris E, Newton J, O'Connor E, Philips A, Philips G, Rees C, Stein B: Cell-phones and brain tumours: 15 reasons for concern. Science, spin and the truth behind interphone. The Radiation Research Trust 2009, 1-38[http://archiv.radiationresearch.org/pdfs/15reasons.aps].

20. Phillips JL, Singh NP, Lai H: Electromagnetic fields and DNA damage. Pathophysiology 2009, 16:79-88.

21. Ruediger HW: Genotoxic effects of radiofrequency electromagnetic fields. Pathophysiology 2009, 16:89-102.

22. Romanelli Ferreira A, Knakievicz T, Pasquali MA, Gelain DP, Dal-Pizzol F, Fernandez CE, de Salles AA, Ferreira HB, Moreira JC: Ultra high frequencyelectromagnetic field irradiation during pregnancy leads to an increase in erythrocytes micronuclei incidence in rat offspring. Life Sci 2006, 80:43-50.

23. Panagopoulos DJ, Chavdoula ED, Nezis IP, Margaritis LH: Cell death induced by GSM $900-\mathrm{MHz}$ and DCS $1800-\mathrm{MHz}$ mobile telephony radiation. Mutat Res 2007, 626:69-78.

24. Balode Z: Assessment of radio-frequency electromagnetic radiation by the micronucleus test in bovine peripheral erythrocytes. Sci Total Environ 1996, 180:81-85.

25. Gadhia PK, Shah T, Mistry A, Pithawala M, Tamakuwala D: A preliminary study to assess possible chromosomal damage among users of digital mobile phones. Electrom Biol Med 2003, 22:149-159.

26. Friedman J, Kraus S, Hauptman Y, Schiff Y, Seger R: Mechanism of shortterm ERK activation by electromagnetic fields at mobile phone frequencies. Biochem J 2007, 405:559-568.

27. Buttiglione M, Roca L, Montemurno E, Vitiello F, Capozzi V, Cibelli G: Radiofrequency radiation $(900 \mathrm{MHz})$ induces egr-1 gene expression and affects cell-cycle control in human neuroblastoma cells. J Cell Physiol 2007, 213:759-767.

28. Salford $L G$, Brun AE, Eberhardt JL, Malmgren L, Persson BR: Nerve cell damage in mammalian brain after exposure to microwaves from GSM mobile phones. Environ Health Perspect 2003, 111:881-883.

29. Nittby H, Brun A, Eberhardt J, Malmgren L, Persson BR, Salford LG Increased blood-brain barrier permeability in mammalian brain 7 days after exposure to the radiation from a GSM-900 mobile phone. Pathophysiology 2009, 16:103-112.

30. Karinen A, Heinavaara S, Nylund R, Leszczynski D: Mobile phone radiation might alter protein expression in human skin. BMC Genomics 2008, 9:77.

31. Blank M, Goodman R: Electromagnetic fields stress living cells. Pathophysiology 2009, 16:71-78.

32. Sokolovic D, Djindjic B, Nikolic J, Bjelakovic G, Pavlovic D, Kocic G, Krstic D, Cvetkovic T, Pavlovic V: Melatonin reduces oxidative stress induced by chronic exposure of microwave radiation from mobile phones in rat brain. J Radiat Res (Tokyo) 2008, 49:579-586.

33. Wdowiak A, Wdowiak L, Wiktor H: Evaluation of the effect of using mobile phones on male fertility. Ann Agric Environ Med 2007, 14:169-172.

34. Agarwal A, Deepinder F, Sharma RK, Ranga G, Li J: Effect of cell phone usage on semen analysis in men attending infertility clinic: An observational study. Fertil Steril 2008, 89:124-128.

35. Huss A, Egger M, Hug K, Huwiler-Muntener K, Roosli M: Source of funding and results of studies of health effects of mobile phone use: Systematic review of experimental studies. Environ Health Perspect 2007, 115:1-4.

36. Muscat JE, Malkin MG, Thompson S, Shore RE, Stellman SD, Mc Ree D, Neugut Al, Wynder : Handheld cellular telephone use and risk of brain cancer. JAMA 2000, 284:3001-3007.

37. Muscat JE, Malkin MG, Thompson S, Shore RE, Neugut Al, Stellman SD, Bruce J: Handheld cellular telephones and risk of acoustic neuroma. Neurology 2002, 58:1304-1306.

38. Inskip PD, Tarone RE, Hatch EE, Wilkosky TC, Shapiro WR, Selker RG, Fine HA, Black PM, Loeffler JS, Linet MS: Cellular-telephone use and brain tumors. N Engl J Med 2001, 344:79-86.

39. Christensen HC, Schuz J, Kosteljanetz M, Poulsen HS, Thomsen J, Johansen C: Cellular telephone use and risk of acoustic neuroma. Am J Epidemiol 2004, 159:277-283.

40. Lonn S, Ahlbom A, Hall P, Feychting M: Mobile phone use and the risk of acoustic neuroma. Epidemiology 2004, 15:653-659.
41. Lonn S, Ahlbom A, Hall P, Feychting M, Swedish Interphone Study Group: Long-term mobile phone use and brain tumor risk. Am J Epidemiol 2005, 161:526-535.

42. Christensen HC, Schuz J, Kosteljanetz M, Poulsen HS, Boice JD, MC Laughlin JK, Johansen C: Cellular telephones and risk for brain tumors: a population-based, incident case-control study. Neurology 2005, 64:1189-1195.

43. Schoemaker MJ, Swerdlow AJ, Ahlbom A, Auvinen A, Blaazas KG, Cardis E, Collatz $\mathrm{H}$, Christensen HC, Feychting M, Hepworth SJ, Johansen C, Klaeboe L, Lonn S, Mc Kinney PA, Muir K, Raitanen J, Salminen T, Thomsen J, Tynes T: Mobile phone use and risk of acoustic neuroma: results of the Interphone case-control study in five North European countries. Br J Cancer 2005, 93:842-848.

44. Lahkola A, Salminen T, Auvinen A: Selection bias due to differential participation in a case-control study of mobile phone use and brain tumors. Ann Epidemiol 2005, 15:321-325.

45. Takebayashi T, Akiba S, Kikuchi Y, Taki M, Wake K, Watanabe S, Yamaguchi N: Mobile phone use and acoustic neuroma risk in Japan. Occup Environ Med 2006, 63(12):802-807.

46. Hepworth SJ, Schoemaker MJ, Muir KR, Swerdlow AJ, van Tongeren MJ, McKinney PA: Mobile phone use and risk of glioma in adults: casecontrol study. Brit Med J 2006, 332:883-887.

47. Schuz J, Bohler E, Berg G, Schlehofer B, Hettinger I, Schlaefer K, Wahrendorf J, Kunna-Grass K, Blettner M: Cellular phones, cordless phones, and the risks of glioma and meningioma (interphone study group, Germany). Am J Epidemiol 2006, 163(6):512-520.

48. Lonn S, Ahlbom A, Christensen HC, Johansen C, Schuz J, Edstrom S, Henriksson J, Lundren J, Wennenberg J, Feychting M: Mobile phone use and risk of parotid gland tumor. Am J Epidemiol 2006 164(7):637-643

49. Klaeboe $L$, Blaasaas $K G$, Tynes $T$ : Use of mobile phones in Norway and risk of intracranial tumours. Eur J Cancer Prev 2007, 16(2):158-164.

50. Lahkola A, Auvinen A, Raitanen J, Schoemaker MJ, Christensen HC, Feychting M, Johansen C, Klaeboe L, Lonn S, Swerdlow AJ, Tynes T, Salminen T: Mobile phone use and risk of glioma in 5 North European countries. Int I Cancer 2007, 120:1769-1775.

51. Hours M, Bernard M, Montestrucq L, Arslan M, Bergeret A, Deltour I, Cardis E: Cell phones and risk of brain and acoustic nerve tumours: The French Interphone case-control study. Rev Epidemiol Sante Publique 2007, 55(5):321-332.

52. Schlehofer B, Schlaefer K, Blettner M, Berg G, Bohler E, Hettinger I, KunnaGrass K, Wahrendorf J, Schuz J: Environmental risk factors for sporadic acoustic neuroma (Interphone Study Group, Germany). Eur I Cancer 2007, 43(11):1741-1747.

53. Sadetzki S, Chetrit A, Jarus-Hakak A, Cardis E, Deutch Y, Duvdevani S, Zultan A, Novikov I, Freedman L, Wolf M: Cellular phone use and risk of benign and malignant parotid gland tumors-a nationwide case-control study. Am J Epidemiol 2008, 167:457-467.

54. Lahkola A, Salminen T, Raitanen J, Heinavaara S, Schoemaker MJ, Christensen HC, Feychting M, Johansen C, Klaeboe L, Lonn S, Swerdlow AJ, Tynes T, Auvinen A: Meningioma and mobile phone use - a collaborative case-control study in five North European countries. Int J Epidemiol 2008, 37:1304-1313.

55. Takebayashi T, Varsier N, Kikuchi Y, Wake K, Taki M, Watanabe S, Akiba S, Yamaguchi N: Mobile phone use, exposure to radiofrequency electromagnetic field, and brain tumour: a case-control study. $\mathrm{Br} J$ Cancer 2008, 98:652-659.

56. Redmayne M, Inyang I, Dimitriaidis C, Benke G, Abramson MJ: Cordless telephone use: implications for mobile phone research. J Environ Monit 2010, 12:809-812.

57. Vrijheid M, Richardson L, Armstrong BK, Auvinen A, Berg G, Carroll M, Chetrit A, Del tour I, Feychting M, Giles GG, Hours M, lavarone I, Lagorio S, Lonn S, McBride M, Parent ME, Sadetzki S, Salminen T, Snchez M, Schlehofer B, Schuz J, Siemiatycki J, Tynes T, Woodward A, Yamaguchi N, Cardis E: Quantifying the impact of selection bias caused by nonparticipation in a case-control study of mobile phone use. Ann Epidemiol 2009, 19:33-42.

58. Morgan RW, Kelsh MA, Zhao K, Exuzides KA, Heringer S, Negrete W: Radiofrequency exposure and mortality from cancer of the brain and lymphatic/hematopoietic systems. Epidemiology 2000, 11:118-127. 
59. Johansen C, Boice J Jr, McLaughlin J, Olsen J: Cellular telephones and cancer-a nationwide cohort study in Denmark. J Natl Cancer Inst 2001, 93:203-207.

60. Schuz J, Jacobsen R, Olsen JH, Boice JD, McLaughlin JK, Johansen C: Cellular telephone use and cancer risk: update of a nationwide Danish cohort. J Natl Cancer Inst 2006, 98:1707-1713.

61. Schuz J, Waldemar G, Olsen JH, Johansen C: Risks for central nervous system diseases among mobile phone subscribers: a Danish retrospective cohort study. PLoS One 2009, 4:e4389.

62. Lloyd-Morgan L: Estimating the risk of brain tumors from cell-phone use: Published case-control studies. Pathophysiology 2009, 16:137-147.

63. Vrijheid M, Armstrong BK, Bedard D, Brown J, Deltour I, lavarone I, Krewski D, Lagorio S, Moore S, Richardson L, Giles GG, Mc Bride M, Parent ME, Siemiatycki J, Cardis E: Recall bias in the assessment of exposure to mobile phones. J Expo Sci Environ Epidemiol 2009, 19:369-381.

64. Hardell L, Carlberg M, Hansson-Mild K: Mobile phone use and the risk for malignant brain tumors: A case-control study on deceased cases and controls. Neuroepidemiology 2010, 35:109-114.

65. Interphone Study: Results update. 2008 [http://www.next-up.org/pdf/ Interphone_IARC_Results_update.pdf ].

66. Hardell L, Carlberg M, Soderqvist F, Hansson-Mild K: Meta-analysis of longterm mobile phone use and the association with brain tumours. Int $J$ Oncol 2008, 32:1097-1103.

67. Khurana VG, Teo C, Kundi M, Hardell L, Carlberg M: Cell phones and brain tumors: a review including the long-term epidemiologic data. Surg Neurol 2009, 72:205-214.

68. Han YY, Kano H, Davis DL, Niranjan A, Lunsford LD: Cell phone use and acoustic neuroma: the need for standardized questionnaires and access to industry data. Surg Neurol 2009, 72:216-222.

69. Kan P, Simonsen SE, Lyon JL, Kestle JR: Cellular phone use and brain tumor: a meta-analysis. J Neurooncol 2008, 86:71-78.

70. Lahkola A, Tokola K, Auvinen A: Meta-analysis of mobile phone use and intracranial tumors. Scand J Work Environ Health 2006, 32:171-177.

71. Hardell L, Carlberg M, Hansson-Mild K: Epidemiological evidence for an association between use of wireless phones and tumor diseases. Pathophysiology 2009, 16:113-122.

72. The Interphone Study Group: Brain tumour risk in relation to mobile telephone use: results of the Interphone international case-control study. Int J Epidemiol 2010, 39:675-694.

73. Saracci $R$, Samet J: Commentary: call me on my mobile phone ... or better not? - a look at the INTERPHONE study results. Int J Epidemiol 2010, 39:695-698.

74. Havas M: Interphone Study: it's not just brain tumors![http://www. magdahavas.com/2010/05/17/interphone_parotid_gland_tumors].

75. Cardis E, Sadetzki S: Indications of possible brain-tumour risk in mobilephone studies: should we be concerned? Occup Environ Med 2011, 68:169-171.

76. Gennaro V, Tomatis L: Business bias: how epidemiologic studies may underestimate or fail to detect increased risks of cancer and other diseases. Int J Occup Environ Health 2005, 11:356-359.

77. Parodi S, Gennaro V, Ceppi M, Cocco P: Comparison bias and dilution effect in occupational cohort studies. Int J Occup Environ 2007, 13:143-152.

78. Hardell L: Wireless phone use and brain tumour risk. In Eur J Oncol Volume 5. Library; 2010:363-378.

79. Czerninski R, Zini A, Syan-Cohen HD: Risk of parotid malignant tumors in Israel (1970-2006). Epidemiol 2001, 22:130-131.

80. Hansson-Mild K, Hardell L, Kundi M, Mattsson MO: Mobile telephones and cancer: is there really no evidence of an association? (review). Int J Mol Med 2003, 12:67-72.

81. Kundi M: Mobile phone use and cancer. Occup Environ Med 2004, 61:560-570.

82. Kundi M, Hansson-Mild K, Hardell L, Mattsson MO: Mobile telephones and cancer-a review of epidemiological evidence. J Toxicol Environ Health Crit Rev 2004, 7:351-384.

83. Hardell L, Carlberg M, Hansson-Mild K: Methodological aspects of epidemiological studies on the use of mobile phones and their association with brain tumors. Open Environ Sci 2008, 2:54-61.

84. Hardell L, Carlberg M, Hansson-Mild K: Re-analysis of risk for glioma in relation to mobile telephone use: comparison with the results of the Interphone international case-control study. J Epidemiol 2010, 1-3.
85. Myung SK, Ju W, McDonnell DD, Lee YJ, Kazinets G, Cheng CT, Moskowitz JM: Mobile phone use and risk of tumors: A meta-analysis. $J$ Clin Oncol 2009, 27:5565-5572.

86. International Agency for Research on Cancer (IARC): The Interphone Study 2010 [http://www.iarc.fr/en/research-groups/RAD/RCAd.html].

87. EEA, Radiofrequency Electromagnetic Fields: EEA Commentary on the Evaluation of the Evidence. March; EEA web item September 17th 2007 Radiation Risk from everyday devices assessed, Copenhagen (2007/08)

88. European Parliament Resolution on Health Concerns Associated with Electromagnetic Fields. 2009 [http://www.europarl.europa.eu], Doc. A60089/2009, archives.

89. Han YY, Gandhi OP, De Salles A, Herberman RB, Davis DL: Comparative assessment of models of electromagnetic absorption of the head for children and adults indicates the need for policy changes. In Eur J Oncol. Volume 5. Library; 2010:301-318.

90. Dubey RB, Hanmandlu M, Gupta SK: Risk of brain tumors from wireless phone use. J Comput Assist Tomogr 2010, 6:799-807.

doi:10.1186/1476-069X-10-59

Cite this article as: Levis et al:: Mobile phones and head tumours. The discrepancies in cause-effect relationships in the epidemiological studies - how do they arise? Environmental Health 2011 10:59.

\section{Submit your next manuscript to BioMed Central and take full advantage of:}

- Convenient online submission

- Thorough peer review

- No space constraints or color figure charges

- Immediate publication on acceptance

- Inclusion in PubMed, CAS, Scopus and Google Scholar

- Research which is freely available for redistribution

Submit your manuscript at www.biomedcentral.com/submit
C Biomed Central 